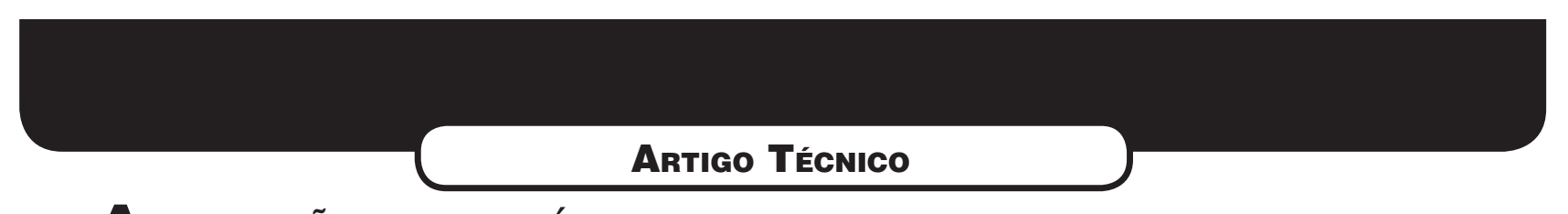

\title{
AvaliaÇÃo de POLÍTICA AMBIENTAL E SUSTENTABILIDADE: ESTUdO dE CASO dO MUNICíPIO dE SANTO ANDRÉ - SP
}

\section{ENVIRONMENTAL POLICY ASSESSMENT AND SUSTAINABILITY: CASE STUDY of SANTO ANDrÉ CITY - SP - BraZIL}

JULIANA PELLEGRINI CEZARE
Bióloga. Iniciação Científica na FSP da USP. Graduação na UNESP - São José do Rio Preto

TADEU FABRICIO MALHEIROS

Engenheiro Civil e Ambiental. Doutor em Saúde Pública. Professor da EESC da USP

ARLINDo PhiLIPPI JR

Engenheiro Civil e Sanitarista. Doutor em Saúde Pública. Professor Titular da FSP da USP

Recebido: 22/01/07 Aceito: 23/10/07

\section{RESUMO}

A gestão da Região Metropolitana de São Paulo tem como um dos desafios resolver a problemática do uso e ocupação do solo em áreas de proteção de mananciais, visando proteção dos recursos hídricos desta região. Este artigo tem como objetivo contribuir para a discussão sobre Avaliação de Estratégia de Desenvolvimento Sustentável, a partir de uma análise das políticas ambientais do Município de Santo André, no contexto da proteção dos recursos hídricos. Propõe-se a verificar, com base nos Princípios de Bellagio, se houve enfoque sistêmico, transparência, participação e engajamento social no processo de formulação e implementação de suas políticas ambientais. Observou-se coerência nas políticas, programas e ações estudadas, entretanto, foram identificadas lacunas que, sobre o enfoque estratégico, representam fraquezas na construção da sustentabilidade local, como no caso da ausência de um sistema consolidado de indicadores de sustentabilidade.

PALAVRAS-CHAVE: Recursos hídricos, sustentabilidade, avaliação estratégica.

\begin{abstract}
The management of the São Paulo Metropolitan Area has as one of the challenges to bring a sustainable solution for land use in watershed protection areas, aiming at regional water resources protection. This paper has the objective to contribute to the discussion about Sustainable Development Strategy Assessment, from an analisys with focus at the environmental policies of the Santo André City - SP Brazil, in the context of water resources protection. For this, the proposal is to verify, based on the Bellagio Principles, the use of systemic approach, transparency, participatory process and social engagement in its policy formulation and implementation process. It was observed coherence within the policies, programmes and actions analysed, nevertheless, gaps were identified, which, within a strategic approach, means weakness for the construction of the local sustainability, as the lack of a consolidated sustainability indicators system.
\end{abstract}

KEYWORDS: Water resources, sustainability, strategic assessment.

\section{INTRODUÇÃO}

A gestão de áreas metropolitanas, como as Regiōes Metropolitanas de Tóquio, Cidade do México, Nova Iorque, São Paulo, entre outras com vários milhões de habitantes, conforme Tabela 1, representa ainda um grande desafio para instituições governamentais e sociedade civil. A concentração demográfica demanda altos investimentos em infraestrutura básica e de serviços, que exigem gerenciamento com atuação dinâmica e integrada.

Estas gigantescas aglomerações urbanas e seus parques empresariais representam pólo concentrador de consumo de recursos naturais, demandando infraestrutura que garanta seu funcionamento em patamares compatíveis a outros centros urbanos num contexto crescente de globalização econômica.

Os resíduos produzidos na operacionalização destas regiōes metropolitanas requerem estratégias que possam compatibilizar a capacidade do ecossistema local em depurar as emissões atmosféricas, resíduos líquidos e sólidos, em concentrações que protejam a saúde pública e a qualidade dos recursos naturais. Com relação à sustentabilidade destes assentamentos humanos, indicadores de disponibilida- de e de qualidade dos recursos hídricos dão sinais efetivos de deterioração e esgotamento de capacidade suporte do conjunto de funçôes do ecossistema.

No Brasil, apesar dos esforços colocados nas políticas públicas de recursos hídricos no âmbito nacional e mais especificamente no Estado de São Paulo, do estágio avançado na implementação dos comitês de bacia hidrográfica, a pressão sobre os recursos hídricos se mantém alta na RMSP, e a resposta do sistema não vem ocorrendo na velocidade necessária.

O crescimento de uso urbano em Áreas de Proteção de Mananciais - APM pode comprometer os 
recursos hídricos, quando ocorre de forma não adequada, como no caso do manancial Billings, localizado dentro da Região Metropolitana de São Paulo - RMSP, onde a taxa de cresci- mento de áreas urbanas consolidadas e não consolidadas, no período de 1989 a 1999, foi, respectivamente, de $27,3 \%$ e $47,9 \%$, indicado na Tabela 2 . Conforme a Tabela 3, os municípios que mais contribuíram neste crescimento foram São Bernardo do Campo e São Paulo, com 854 e 664 ha de expansão urbana, respectivamente.

Tabela I - População nas maiores aglomerações urbanas, ordenadas em ordem decrescente conforme população em 2003

\begin{tabular}{ccccc}
\hline Regiōes & País & \multicolumn{3}{c}{ População (em 10 ${ }^{6}$ habitantes) } \\
Metropolitanas & & 1975 & 2003 & 2015 \\
\hline Tóquio & Japão & 26,6 & 35,0 & 36,2 \\
Cidade do México & México & 10,7 & 18,7 & 20,6 \\
Nova Iorque & Estados Unidos da América & 15,9 & 18,3 & 19,7 \\
São Paulo & Brasil & 9,6 & 17,9 & 20,0 \\
Mumbai (Bombaim) & Índia & 7,3 & 17,4 & 22,6 \\
Nova Délhi & Índia & 4,4 & 14,1 & 20,9 \\
Calcutá & Índia & 7,9 & 13,8 & 16,8 \\
Buenos Aires & Argentina & 9,1 & 13,0 & 14,6 \\
Xangai & China & 11,4 & 12,8 & 12,7 \\
Jakarta & Indonésia & 4,8 & 12,3 & 17,5 \\
\hline
\end{tabular}

Fonte: Naçōes Unidas, 2004

Tabela 2 - Expansão urbana na Bacia Hidrográfica da Billings no período de 1989 a 1999

\begin{tabular}{cccc}
\hline Categoria & $\begin{array}{c}\text { Área em 1999 } \\
\text { (ha) }\end{array}$ & $\begin{array}{c}\text { Incremento no } \\
\text { período 1989-1999 }\end{array}$ & $\begin{array}{c}\text { Incremento no } \\
\text { período 1989-1999 } \\
(\%)\end{array}$ \\
\hline Áreas urbanas consolidadas & $1.653,66$ & 711,92 & 47,91 \\
Áreas urbanas não consolidadas & $6.874,60$ & 1474,94 & 27,29 \\
Áreas de ocupação dispersa & $3.263,52$ & 440,49 & 13,17 \\
Solo exposto & 57,56 & 30,71 & 49,86 \\
Mineração & 156,89 & 24,75 & 12,83 \\
Campo antrópico/várzea & $3.541,50$ & 288,34 & 6,98 \\
Mata Atlântica primária e secundária & $30.889,34$ & 616,24 & 1,89 \\
Reflorestamento & 398,35 & 210,09 & 111,60 \\
Indústrias & 109,06 & 10,51 & 10,66 \\
\hline
\end{tabular}

Fonte: ISA, 2002. (1) em relação à área da categoria em 1989

Tabela 3 - Contribuição dos municípios no componente de expansão urbana total (áreas urbanas consolidadas e não consolidadas) da Bacia Hidrográfica da Billings no período 1989-1999

\begin{tabular}{ccc}
\hline Municípios & Área (ha) & $\%(1)$ \\
\hline São Bernardo do Campo & 854,25 & 39,06 \\
São Paulo & 664,55 & 30,39 \\
Ribeirão Pires & 229,52 & 10,50 \\
Santo André & 216,85 & 9,92 \\
Rio Grande da Serra & 161,45 & 7,38 \\
Diadema & 60,17 & 2,75 \\
Total & $2.186,86$ & 100,00 \\
\hline
\end{tabular}

Fonte: ISA, 2002. (1) em relação à expansão urbana verificada na Bacia 
Como proteger os recursos hídricos desta região e ao mesmo tempo responder às demandas intramunicipais e intrametropolitanas por infraestrutura habitacional, de saneamento, de transporte, de serviços em geral; reduzir, portanto, o índice de vulnerabilidade social e ambiental?

Este desafio requer a inserção da questão dos Recursos Hídricos na agenda das diversas secretarias municipais, de integração regional de esforços, e a percepção e internalização, por parte dos atores governamentais e não governamentais, de que um modelo de gestão fragmentado e com enfoque de cima para baixo, é uma ameaça à sustentabilidade da região como um todo. Promover mudanças tão significativas requer discutir espaços de poder nos âmbitos local e regional, há tanto tempo enraizados nas estruturas gerenciais do governo e de associaçōes de representações civis; requer discutir o modelo de relaçôes governo-governo, lideranças e sociedade civil, governo e sociedade civil.

Nestas últimas décadas, verifica-se nos âmbitos internacional e nacional avanços recentes na formulação e implementação de políticas mais focadas no contexto da proteção ambiental, alinhados à promoção da saúde pública, da justiça social e viabilidade econômica. No entanto, estudos apontam lacuna no que se refere às ações de avaliação destes esforços, dificultando que se estabeleçam mecanismos de melhoria e avanços no processo de tomada de decisão voltados ao desenvolvimento sustentável (Philippi Jr et al, 2005; Dalal-Clayton \& Bass, 2002).

O processo do desenvolvimento local requer criar sistemas adaptativos à própria dinâmica atual das cidades; balancear prioridades sociais, ambientais e econômicas; ampliar gestão participativa; investir em capacitação de recursos humanos para gestão da sustentabilidade local. (Malheiros, 1996).

Assim, torna-se necessário dispor de informações consistentes sobre os avanços dos Países, Estados e Municípios rumo ao desenvolvimento sustentável, para que se possa orientar o estabelecimento de políticas públicas e de governo coerentes, num esforço orquestrado e sinérgico. Portanto, é essencial a criação de um modelo de avaliação para a orientação da tomada de decisões e sua inserção no processo de gestão ambiental, dentro dos princípios do desenvolvimento sustentável (Philippi Jr, Malheiros \& Aguiar, 2005).

Um enfoque estratégico para a promoção da sustentabilidade local consiste em fomentar processo de estabelecimento de visão de futuro e metas prioritárias para alcançar o desenvolvimento em bases sustentáveis. Deve ser construído de forma interativa e consensual. Para cumprir tais metas, o sistema deve proporcionar um conjunto coordenado de mecanismos institucionais e de informação, que proporcionem um sistema participativo com monitoramento e aprendizagem, dentro de processo de melhoria contínua.

As estratégias devem seguir modelo cíclico de aperfeiçoamento contínuo, por meio de avaliação dos processos e resultados, possibilitando novos debates sobre questões e necessidade chaves, reflexão e revisão de visão de desenvolvimento, tomada de decisão e ajuste do sistema.

Portanto, analisar sustentabilidade pressupóe determinar os estados da sociedade, economia e ambiente, identificando e prognosticando resistências, fraquezas, ameaças e oportunidades, num contexto onde a questão central está em ter informações sobre os impactos e resultados da implementação da estratégia municipal de desenvolvimento, pensada com enfoque de construção de bases sustentáveis.

Segundo Philippi Jr et al, (2004), os municípios devem desenvolver suas próprias estratégias de desenvolvimento sustentável e indicadores para sua avaliação, de acordo com as suas características e escalas locais. A construção e utilização dos indicadores de desenvolvimento sustentável para diagnóstico da realidade local, visando orientação das políticas públicas e implementação da Agenda de Desenvolvimento Sustentável, é um processo permanente e em contínuo desenvolvimento.

Desta forma, este artigo tem como objetivos: (i) contribuir para a discussão sobre avaliação de estratégia de desenvolvimento sustentável; (ii) discutir políticas, planos, programas e projetos ambientais do Município de Santo André e verificar se foram orientados por visão de desenvolvimento sustentável, por meio de enfoque sistêmico, questôes de transparência, participação e engajamento social; (iii) contribuir para as metas e objetivos do projeto SIADES - Sistema de Informações Ambientais para o Desenvolvimento
Sustentável, da Faculdade de Saúde Pública, com apoio do ProDoc-Capes.

A escolha da gestão municipal de Santo André como estudo de caso deveu-se ao fato do esforço que vem sendo empreendido, tanto pelo governo local, quanto pela sociedade civil, nos últimos anos, na construção da sustentabilidade local e regional deste município. Neste sentido, este estudo em questão possibilita que lições aprendidas possam melhor orientar gestôes municipais vizinhas, no contexto de regiōes metropolitanas.

O fato do Município estar inserido na Região Metropolitana de São Paulo e possuir 55\% de seu território em Área de Proteção e Recuperação dos Mananciais (PMSA, 2004b), tem significância na discussão da sustentabilidade urbana e de gestão dos recursos hidrícos, uma vez que representa espaço potencial de conflitos sociais, econômicos e ambientais. O estudo de caso de avaliação do processo de Gestão Ambiental para o Município de Santo André insere-se, assim, no contexto de política de interesse local e metropolitano, e tem como foco os esforços em ações de proteção da área de mananciais da Região Metropolitana de São Paulo.

\section{METODOLOGIA}

Segundo Gil (1996), o estudo de caso é caracterizado pelo estudo profundo e exaustivo de um ou de poucos objetos, de maneira que permita o seu amplo detalhamento. Para o autor o estudo de caso tem como vantagem flexibilidade do planejamento, que mantém o pesquisador atento a novos elementos; a ênfase na interpretação em contexto, voltado para a multiplicidade de dimensões de um determinado problema, focalizando-o como um todo; e a simplicidade de coleta e análise de dados.

Portanto, dentro do objetivo da pesquisa, que tem como foco o olhar ambiental sobre a estratégia de desenvolvimento adotada pelo Município de Santo André, foram consultadas diretrizes e ações coordenadas pelo Governo local, incluindo aqui as políticas ambientais, planos, programas e projetos desenvolvidos.

Para esta pesquisa foram então selecionadas duas políticas mais focados no desenvolvimento urbano e ambiental: o Plano Diretor, Lei no 8696/04 e a Política Municipal de Gestão e Sa- 
neamento Ambiental de Santo André, Lei $n^{\circ} 7733 / 98$. A primeira pelo fato de regulamentar o uso e ocupação do solo e definir diretrizes e açōes para o desenvolvimento urbano, ordenando a expansão urbana dentro de critérios de justiça social, proteção ambiental e viabilidade econômica. A segunda por estabelecer o Sistema Municipal de Gestão e Saneamento Ambiental do município de Santo André.

Foram também selecionados para análise os projetos Gerenciamento Participativo de Areas de Mananciais GEPAM e Santo André - Cidade Futuro, devido à suas abrangências, ao caráter participativo, e seus aspectos inovadores para promoção do desenvolvimento em bases sustentáveis.

Também foram selecionadas duas ações estratégicas da gestão ambiental no município, que são a inserção e integração da questão ambiental no componente institucional da gestão municipal, com a instituição do SEMASA - Serviço Municipal de Saneamento de Santo André, e a criação da Subprefeitura de Paranapiacaba e Parque Andreense - SPPA. O documento Sumário de Dados (PMSA, 2004 a, b) foi examinado para complementar avaliação sobre o sistema de informação do município.

Para a análise qualitativa dos resultados obtidos, utilizou-se os Princípios de Bellagio, referencial internacionalmente reconhecido, como instrumento de avaliação de processo rumo ao desenvolvimento sustentável (Hardi \& Zdan, 1997).

Estes Princípios foram formulados em novembro de 1996, por um grupo internacional de especialistas em avaliação e pesquisadores que se reuniram no Centro de Estudo e Conferência da Fundação Rockefeller em Bellagio, Itália, com a finalidade levantar o estado da arte, revisar os dados e as diferentes iniciativas de avaliação de sustentabilidade e sintetizar a percepção geral sobre os principais aspectos relacionados à avaliação de desenvolvimento sustentável (Dalal-Clayton \& Bass, 2002).

São dez os princípios selecionados que servem como orientação para avaliar e melhorar a escolha, utilização, interpretação e comunicação de indicadores (Figura 1). Eles foram formulados com a intenção de serem utilizados na implementação de projetos de avaliação de iniciativas de desenvolvimento, desde o nível comunitário, chegando até as experiências internacionais, incluindo os níveis intermediários (Van Bellen, 2002).

O princípio 1 refere-se ao ponto inicial, onde deve-se construir uma visão coletiva do que seja sustentabilidade e estabelecer as metas que revelem uma definição prática desta visão em termos do que seja relevante para a tomada de decisão. Os princípios 2 até 5 tratam de conteúdo e da necessidade de repensar o sistema por inteiro com foco em questôes prioritárias. Os princípios 6 até 8 lidam com a questão-chave do processo de desenvolvimento em bases sustentáveis que é a participação social efetiva e capacitada, enquanto que os princípios 9 e 10 se referem à necessidade de estabelecer capacidade contínua de avaliação.

\section{O Município de Santo André}

O Município de Santo André localiza-se na Região Metropolitana de São Paulo - RMSP (Figura 2) e integra juntamente com São Bernardo, São Caetano do Sul e Diadema, o chamado ABCD paulista, uma das mais avançadas áreas industriais da América Latina. Possui uma população estimada de 669.592 habitantes e área total de $175 \mathrm{~km}^{2}$ (IBGE, 2005).

Do território total do município, $55 \%$ está inserido na Bacia Hidrográfica Billings, a qual possui importância fundamental não só para o Município, mas também para toda a região, pois tem como função abastecimento de 1,5 milhão de pessoas da Grande São Paulo, produção de energia elétrica e abastecimento industrial. Em face da necessidade de conservação dos fragmentos florestais, cursos d'água e nascentes existentes na bacia, visando a sustentabilidade do manancial, esta regiāo foi declarada Área de Proteção aos Mananciais da Região Metropolitana de São Paulo, pelas Leis Estaduais no $898 / 75$ e $1.172 / 76$. Esta região do município de Santo André caracterizase pela baixa densidade populacional, em função da distância da área urbana central e da legislação ambiental de uso e ocupação do solo mais restritiva. Destaca-se ainda a Vila de Paranapiacaba, tombada pelo CONDEPHAT em 1997, e, portanto, sua importância no contexto sócio-ambiental da gestão desta região (PMSA, 2004b).

Seguindo orientações traçadas pelos movimentos internacionais, como a Rio-92, Cairo-94, Istambul-96, entre outros, e ações e legislações brasileiras, o Município de Santo André vem desenvolvendo nos últimos anos várias ações que se propõem a contribuir com o desenvolvimento do município rumo ao desenvolvimento sustentável.

A adoção de políticas públicas buscando a sustentabilidade urbana implica em repensar o modelo de desenvolvimento adotado e as interfaces da questão ambiental com os componentes social e econômico. Trata-se, portanto, de gestão sustentável do espaço urbano, tendo em vista estratégias de inclusão social, eqüidade no acesso aos recursos ambientais e a realização da justiça ambiental.

Desta maneira, o governo municipal de Santo André estabeleceu como meta fundamental a democratização dos processos decisórios por meio da participação social. Para consolidar uma democracia participativa local, retomaram-se as atividades do orçamento participativo em 1997 e criaram-se diversos conselhos municipais deliberativos, como por exemplo, Conselho Municipal de Gestão e Saneamento Ambiental-Comugesan, Conselho Municipal de Gestão de Política Urbana - CMPU, Conselho Municipal de Habitação, entre outros.

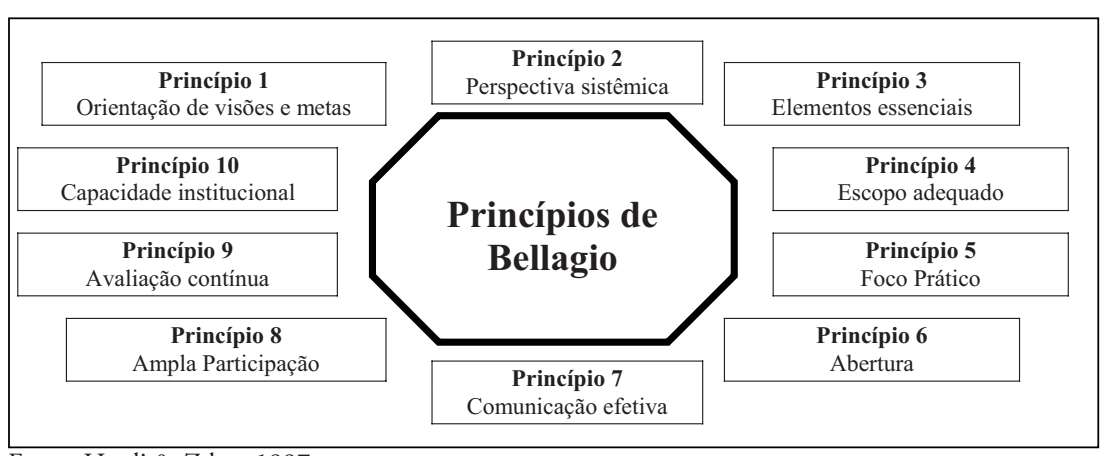

Fonte: Hardi \& Zdan, 199

Figura I- Princípios de Bellagio 


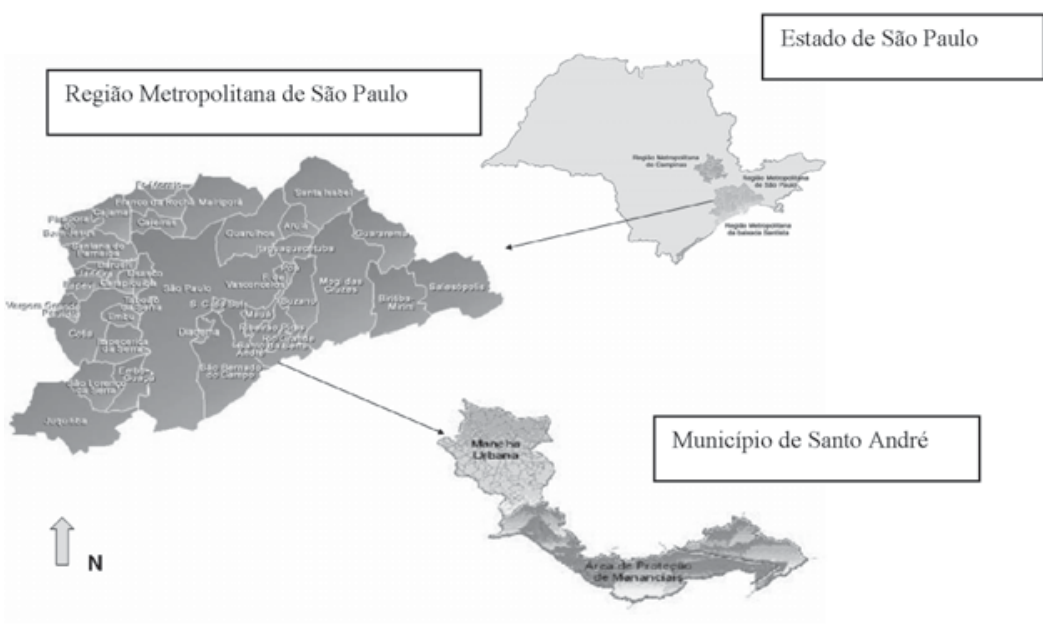

Fonte: I'MSA 2UUS

Figura 2 - Mapa da Região Metropolitana de São Paulo, com destaque para - Município de Santo André

Vários programas desenvolvidos pela municipalidade visam fomentar comunidades da periferia e de regiōes pobres a desenvolverem suas capacidades, por meio de cursos de alfabetização, profissionalizantes, para cooperativas e para empreendedores locais. Estas capacitações são potencializadas com outros programas de apoio como Banco do Povo, Banco de Crédito Solidário e Assessoria e Consultoria para pequenos negócios.

\section{Estratégias ambientais empreendidas relacionadas à proposta de construção do desenvolvimento em bases sustentáveis no Município de Santo André}

(i) Sumário de Dados de Santo André: criado em 1990, trata-se de uma publicação que reúne indicadores de todas as secretarias municipais de Santo André, e visa à universalização da informação (PMSA, 2004a).

(ii) Política Municipal de Gestão e Saneamento Ambiental: implementada em 14 de outubro de 1998, a Política Municipal de Gestão e Saneamento de Santo André, Lei municipal no 7733, instituiu o Sistema Municipal de Gestão e Saneamento Ambiental - SIMGESA, estabeleceu o Plano de Gestão e Saneamento Ambiental - PLAGESAN, e criou o Fundo Municipal de Gestão e Saneamento Ambiental - FUMGESAN.

(iii) Projeto Gerenciamento Participativo de Áreas de Mananciais - Gepam: é uma parceria entre o Centro de Assentamento Humano da Universidade de British Columbia-CHS/UBC, a Agência Canadense para o Desenvolvimento Internacional - CIDA e a Prefeitura Municipal de Santo André - PMSA. Implementado em 1998, com a finalidade de apoiar e fomentar as premissas das políticas públicas de melhoria da qualidade social, econômica e ambiental, para a população residente nas áreas de proteção e recuperação aos mananciais.

(iv) Serviço Municipal de Saneamento Ambiental de Santo André - SEMASA: em 1999 ampliaram-se as atribuiçôes da autarquia responsável pelo abastecimento de água e coleta de esgoto da cidade, o SEMASA, que passou de Serviço Municipal de Água e Saneamento para Serviço Municipal de Saneamento Ambiental. O saneamento, entendido até então como serviço de abastecimento de água e esgotamento sanitário, ganha uma perspectiva mais ampla para o município, a do saneamento ambiental, abrangendo ações relativas à proteção do meio ambiente e à promoção da qualidade ambiental.

(v) Projeto Santo André Cidade Futuro: desenvolvido em 1999, é um conjunto de ações estratégicas de planejamento urbano e de investimento em infra-estrutura que visa qualificar a cidaDá direção estratégica de visão de futuro para o desenvolvimento municipal com horizonte para o ano de 2020.

(vi) Subprefeitura de Paranapiacaba e Parque Andreense: é um de para o desenvolvimento sustentável. órgão descentralizado responsável pela gestão pública e ambiental das regióes de Paranapiacaba e Parque Andreense. Os objetivos iniciais da SPPA são promover o desenvolvimento sócioeconômico ambiental sustentável de Paranapiacaba, Parque Andreense e região; promover inclusão social na região; integrar plenamente a população da região ao contexto municipal; prestar serviços públicos de forma eficaz com qualidade; instituir modelo de gestão descentralizada para áreas ambientalmente protegidas; promover a conservação da Área de Proteção de Mananciais; promover a modernização administrativa; transformar a Vila de Paranapiacaba em um pólo turístico (PMSA \& CIDA, 2004).

(vii) Plano Diretor Participativo de Santo André: o processo de discussão pública do Plano Diretor Participativo - PDP se desenvolveu ao longo de três anos, 2002 a 2004, buscando viabilizar com a participação e a contribuição da população, um município com desenvolvimento econômico, justiça social e qualidade ambiental. $\mathrm{O}$ Plano Diretor Participativo de Santo André versa e dá regra ao desenvolvimento urbano do município, com base em leis superiores, Constituição Federal, Estatuto da Cidade e a Lei Orgânica do Município de Santo André. Por sua vez, o Plano Diretor dispóe e define diretrizes para a elaboração de leis posteriores que complementarão o conjunto da legislação urbanística municipal (PMSA, 2003b).

Com base na orientação dos Princípios de Bellagio, o que se verificou, portanto, com esta pesquisa, conforme ilustrado na Figura 3 e no Tabela 4 é que: (i) O Projeto Cidade Futuro estabeleceu visão de futuro para o município e, em conjunto com o Projeto Gepam, Plano Diretor, Política Municipal de Gestão e Saneamento, Subprefeitura de Paranapiacaba e Parque Andreense e Semasa, proporcionou revisão do modelo e sistema vigentes e estabeleceu metas e prioridades para o planejamento estratégico do município; (ii) Quanto à questão da participação da sociedade: os projetos Cidade Futuro e Gepam introduziram metodologia participativa na administração municipal; a publicação do Sumário de Dados e os cursos realizados pelo SEMASA proporcionaram comunicação para a população, capacitando-a para tomada de decisão; criação do 
Centro de Referências garante espaço de engajamento da população; e as políticas de desenvolvimento urbano (plano diretor) e ambiental estabelecem as bases do Sistema de Informação que proporcionará oportunidade de ampla participação da sociedade e transparência de gestão; (iii) Institucionalmente o Sumário de Dados, Plano Diretor, Política Ambiental, Gepam, Semasa e Subprefeitura de Paranapiacaba e Parque Andreense proporcionam mecanismos de capacitação institucional e de potencial de avaliação continua do processo de desenvolvimento do município com base nos princípios da sustentabilidade.

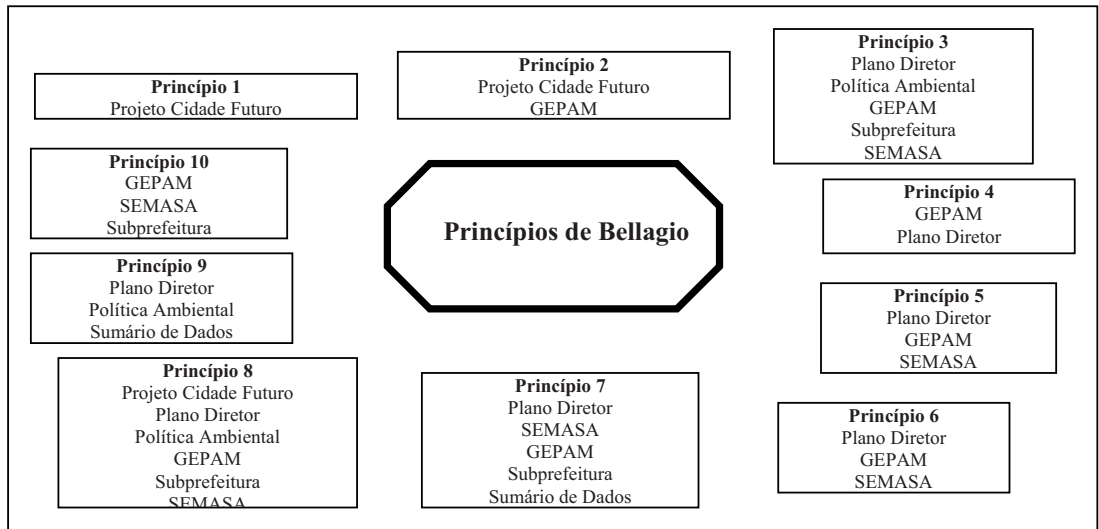

Fonte: Autores

Figura 3 - Relação de ações municipais com os Princípios de Bellagio

Tabela 4 - Estratégias estudadas, relação com os Princípios de Bellagio e observações relevantes, referentes ao Município de Santo André

\begin{tabular}{c}
\hline Estratégia \\
\hline (i) Sumário de Dados \\
(ii) Política Municipal de Gestão e \\
Saneamento Ambiental \\
(iii) Projeto Gerenciamento \\
Participativo de Áreas de \\
Mananciais - Projeto Gepam
\end{tabular}

(iv) Serviço Municipal de

Saneamento Ambiental de Santo André - SEMASA

(v) Projeto Santo André Cidade Futuro

(vi) Subprefeitura de Paranapiacaba e Parque Andreense

3, 7, 8, 9 e 10

$3,5,6,7,8$ e 10

1,2 e 8

$2,3,4,5,6,7,8$ e 10 rincípios de Bellagio

relacionados

3,8 e 9

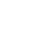




\section{A dinâmica no município para construção de bases para 0 desenvolvimento sustentável}

A construção do desenvolvimento em patamares de sustentabilidade sócio-econômica e ambiental pressupõe que a sociedade discuta e decida qual modelo de sustentabilidade almeja e adote decisões e ações nessa direção. A análise da sustentabilidade implica, sobretudo, em uma abordagem local das várias combinações na complexa estrutura dos ecossistemas. Envolve a idéia de manutenção dos estoques da natureza, ou a garantia de sua reposição por processos naturais ou artificiais, tornando essencial conhecer a capacidade suporte do ambiente.

Para tanto, é necessário levantar quais aspectos humanos e ecológicos se encontram ou contribuem para situações sustentáveis e insustentáveis; quais ações devem ser adotadas visando corrigir os problemas que pressionam para patamares de insustentabilidade. A adoção de políticas e ações visando o desenvolvimento sustentável só será efetiva se o conceito de sustentabilidade for operacionalizado e se houver um suporte para avaliar os avanços em direção aos objetivos traçados. (Siena, 2002).

No estudo de caso de Santo André, verificou-se que comunidade e governo, por meio de discussões realizadas pelo Projeto Cidade Futuro, buscaram consenso e definiram visão de futuro do município e metas de curto, médio e longo prazos. Desde então, o município vem colocando esforços em modelo de desenvolvimento que busca incorporar os princípios de equidade social, ambiente saudável e direito à cidade e ao trabalho, para garantir qualidade de vida para as presentes e futuras geraçôes. Constatou-se que as metas estabelecidas foram incorporadas pelo Plano Diretor, portanto, esforços empenhados estão focados para um objetivo comum.

Observou-se que o Projeto Gepam identificou, por meio da participação da comunidade das áreas de mananciais e técnicos, problemas econômicos e sociais enfrentados pelos moradores e áreas ambientalmente sensíveis. O Projeto Cidade Futuro, também por meio de processo participativo identificou fragilidades, principalmente na área urbana.
No âmbito ambiental a Política Municipal de Gestão e Saneamento Ambiental e o Plano Diretor estimulam a busca pela identificação de ameaças e proposição de ações, por meio da elaboração do Plano Municipal de Gestão e Saneamento Ambiental Plagesan. Entretanto, não foi localizada documentação com prognósticos de açōes para análise de estratégias, nem indicadores para seu monitoramento. Desse modo, a gestão municipal não favorece condições adequadas para o estabelecimento de mecanismos de reajuste do processo de construção de desenvolvimento em bases sustentáveis, devido à ausência do conhecimento das mudanças e dos custos e benefícios de tais açôes.

Quanto à questão sócio-ambiental, constatou-se a preocupação da Administração Municipal em promover a inclusão social, por meio da realização de cursos de alfabetização e capacitação voltados para populações carentes, conforme descrito nos resultados das análises do Projeto Gepam e das ações da Subprefeitura de Paranapiacaba e Parque Andreense.

O Plano Diretor Participativo, também contribuiu para esta questão, por meio da instituição de vários instrumentos que fomentam a inclusão social: Política Municipal de Habitação, consolidação de Zonas Especiais de Interesse Social, identificação de Zona de Recuperação Urbana, criação do Conselho Municipal de Política Urbana.

Quanto à questão econômico-ambiental, observou-se esforço conjunto da Subprefeitura de Paranapiacaba e Parque Andreense - SPPA e o Projeto Gepam, em tornar a Vila de Paranapiacaba em espaço turístico, por meio da promoção de cursos de capacitação em diversas áreas do turismo, como por exemplo, formação de guias turísticos e artesanato, e estímulo e fomento de empreendedores nesta área.

Cabe ressaltar que esta preocupação também aparece no Plano Diretor, que procura incentivar, por meio da Política de Desenvolvimento Econômico, a recuperação do pólo industrial, principalmente o petroquímico; o fortalecimento das atividades turísticas, principalmente na área de proteção aos mananciais. Faz-se necessária ainda, implementação de avaliação ambiental estratégica com relação aos impactos potenciais destas políticas no contexto da Área de Proteção aos Mananciais da
Região Metropolitana de São Paulo.

Verifica-se, também, esforços para integração do componente ambiental na gestão do saneamento municipal e descentralização da política e gestão ambiental por meio da criação do Serviço Municipal de Saneamento Ambiental - Semasa e da Subprefeitura de Paranapiacaba e Parque Andreense - SPPA, respectivamente, conferindo assim autonomia na escolha e definição sobre as prioridades ambientais e diretrizes de ações nos planos, programas e projetos. Somada a este fator, está a instituição da Política Municipal de Gestão e Saneamento, que estabelece por lei: Sistema Municipal do Meio Ambiente - SISMUMA; educação ambiental; prevenção, licenciamento, fiscalização e controle ambiental. Assim, busca garantir a qualidade do meio e, portanto, melhoria da saúde pública e qualidade de vida da população.

Quanto à participação social, o histórico das políticas públicas, planos, programas e projetos em Santo André apontam preocupação do governo e sociedade em considerar a democratização dos processos decisórios, por meio de inúmeras ações: instituição de diversos conselhos municipais deliberativos, sendo alguns garantidos por lei, como por exemplo, o Conselho Municipal de Gestão e Saneamento Ambiental - Comugesan; investimento no Projeto Gepam, com a finalidade de aplicação de gerenciamento participativo; e a construção do Centro de Referência em Saneamento Ambiental, espaço disponível à população para pesquisas, palestras e cursos na área ambiental. Além disso, há realização de cursos de capacitação para integrantes dos conselhos municipais, com vistas a melhorar o processo de representação e decisório nestes espaços, bem como integração das agendas destes conselhos a partir de 2004.

Santo André não dispõe ainda de um sistema de indicadores de sustentabilidade, apesar das leis municipais no 7733/98 e 8.696/04. A primeira implantou o Sistema Municipal de Gestão de Saneamento Ambiental, e estabeleceu que este deve proporcionar o desenvolvimento de um banco de dados organizado, permitindo monitoramento ambiental eficiente. A segunda estabeleceu a formação de um Sistema de Informaçôes Municipal e também instituiu os planos setoriais do Plano Diretor, determinando que cada plano 
setorial deve implementar seu sistema de informação, permitindo assim sua construção em bases confiáveis e posterior avaliação e revisão.

Indicadores permitem monitorar as interaçóes entre o componente de meio ambiente e sócio-econômico, bem como uma base de dados para planejamento estratégico e análise de políticas para identificarem as vias de desenvolvimento sustentável. Desta forma, ajuda governos a formularem e monitorarem políticas econômicas com maior eficácia, a determinar regulamentações ambientais estratégicas de gestão de recursos mais eficazes e a utilizar os impostos e subsídios com maior eficiência. Oferece, também, uma forma de melhorar o diálogo político entre diferentes atores, ao fornecer um sistema transparente de informação sobre a relação entre as atividades humanas e ambientais.

Quanto à questão institucional, entende-se que o Projeto Gepam contribuiu para a administração pública ao introduzir metodologia de envolvimento da comunidade na conservação do ambiente, incluindo capacitação de técnicos da equipe de gestores para a realização de diagnósticos e planejamentos participativos; investimento na formação ambiental de professores por meio da implementação e desenvolvimento de técnicas formativas de gestão participativa e cidadã, visando o aprimoramento da educação ambiental do município. Além disso, promoveu a aquisição de novos softwares e treinamento da equipe técnica do Semasa em Sistema de Informação Geográficos, com a finalidade de mapeamento das áreas ambientalmente sensíveis.

\section{CONCLUSÃO}

A discussão apresentada sobre as estratégias municipais foi realizada com base nos Princípios de Bellagio e possibilitou identificar coerência entre políticas, planos, programas e ações estudadas, com estabelecimento de visão de futuro, participação social e transparência de gestão.

A análise realizada possibilitou identificar também, determinadas lacunas para políticas, projetos e ações, que sob o enfoque estratégico, podem representar fraqueza na construção da sustentabilidade do local, como por exemplo, fragilidade no conjunto de indicadores para avaliação integrada da questão ambiental, social, econômica e institucional. Esforços devem ser colocados na construção de um conjunto de indicadores sistêmicos que permitam, de forma integrada, diagnosticar e prognosticar as condições dos recursos naturais e humanos, os aspectos institucionais, bem como avaliar e comunicar os resultados da gestão (Figura 4).

Alguns pontos chaves ainda por serem analisados são: o funcionamento do processo de aprendizagem do sistema, para possibilitar correção de rumo e melhoria contínua; o desenvolvimento de sistema de indicadores e sua incorporação em políticas públicas; integração institucional nos planos horizontal e vertical, principalmente no contexto da Região Metropolitana de São Paulo.

A inserção da questão ambiental de forma integrada no sistema de saneamento ambiental proporciona potencial significativo para o municipal lidar com a complexidade do sistema ambiental, pois permite ações mais focadas, maior autonomia e capacidade institucional.

Outro ponto forte a ser destacado, identificado por esta pesquisa, é o estabelecimento da Política Municipal de Gestão e Saneamento Ambiental, Lei $\mathrm{n}^{\circ} 7733 / 98$, que instituiu o sistema municipal de meio ambiente, ampliando instrumentos e mecanismos para promoção da saúde ambiental e qualidade de vida da sociedade. Neste mesmo olhar, a política municipal de desenvolvimento urbano, o Plano Diretor, Lei no 8696/04, também representa consolidação da estratégia empreendida, pois traz princípios de integração das questôes sociais, ambientais, econômicas e institucionais, entendidos como fundamentais na promoção do desenvolvimento do município em bases sustentáveis.

Além disso, a consolidação da participação da comunidade, por meio dos diversos conselhos criados, e o processo de capacitação realizado proporcionam efetivo espaço de engajamento da sociedade na construção da qualidade social, ambiental e econômica do município, e permitem que a população atue como agentes planejadores e multiplicadores, contribuindo para a geração de ações positivas de cidadania e ética.

A condição geográfica do município na Região Metropolitana de São Paulo e em Áreas de Proteção de Mananciais é um ponto a ser gerido de forma estratégica, dentro de contexto e enfoque regional. $\mathrm{O}$ crescimento urbano dos municípios vizinhos representa pressão sobre os recursos hídricos desta área de proteção de mananciais e, também, sobre os recursos naturais da região metropolitana, o que exige política e gestão coordenada neste âmbito de atuação.

Para finalizar, o conjunto de experiências que a pesquisa analisou, representa diferencial no processo de gestão sócio-ambiental do município. O Projeto Gepam, por exemplo, revelou-se um instrumento significativo para o gerenciamento destas áreas, e esforços devem ser colocados na sua aplicação em outras áreas do município e municípios vizinhos. As experiências bem sucedidas devem ser aproveitadas

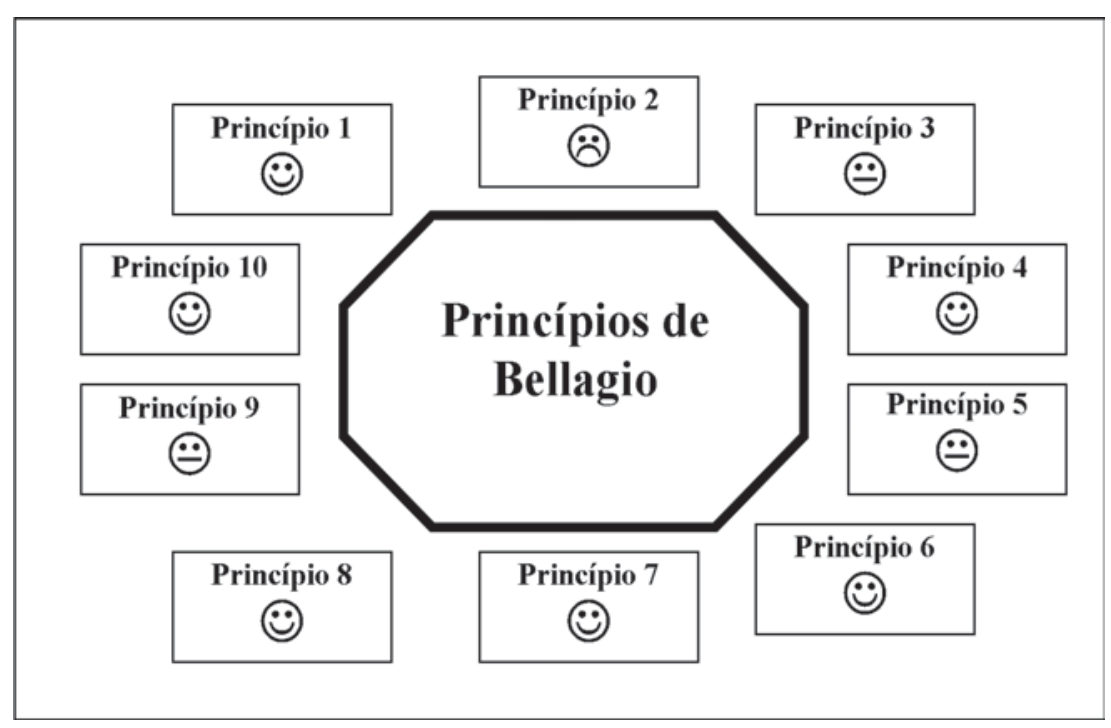

Fonte: Autores. (-) Atende; $(\odot)$ Atende parcialmente; $(*)$ Não Atende

Figura 4 - Atendimento das estratégias municipais aos princípios de Bellagio 
como benchmark, destacando-se que as dificuldades e características metropolitanas dos municípios desta região representam espaço importante para a troca de experiência e avanços no campo da política e gestão ambiental.

\section{REFERÊNCIAS}

DALAL-CLAYTON B., BASS S. Sustainable Development Strategies: A resource Book [online]. London: Earthscan Publications Ltd. Internacional Institute for Environment and Development, 2002. Available on URL <http://www.nssd.net> 06/08/2005.

GIL AC. Como Elaborar Projetos de Pesquisa. São Paulo: Atlas; 1996.

HARDI P., ZDAN T. (ed.) Assessing sustainable development: principles in pratice [online]. Winnipeg, Canadá: International Institute for Sustainable Development, 1997. Available on <http://www.iisd.ca/about/prodcat/ principleinpractice.pdf>. 04/08/2001.

IBGE-INSTITUTO BRASILEIRO DE GEOGRAFIA E ESTATÍSTICA. Cidades@. Rio de Janeiro, 2005. Disponível em URL <http://www. ibge.gov.br> 21/06/2005.

ISA-INSTITUTO SOCIOAMBIENTAL. Billings 2000: Ameaças e Perspectiva para o Maior Reservatório de Agua da Região Metropolitana de São Paulo. São Paulo: Instituto Socioambiental; 2002.

MALHEIROS TF. Guideline for small town sustainable development in Brazil. Karlsruhe - Alemanha. Dissertação de mestrado apresentada a Universidade de Karlsruhe. 1996.

NAÇŐES UNIDAS. Urban Agglomerations 2003. New York: Naçōes Unidas; 2004. [online]. Available on URL http://www.un.org/esa/population/publications/wup2003/2003urban_agglo. htm 06/08/2005.
PHILIPPI JRA. et al. Gestão ambiental municipal: subsídios para estruturação de sistema municipal de meio ambiente. Vol. 4. Salvador: CRA - Centro de Recursos Ambientais; 2004.

PHILIPPI Jr A., MALHEIROS TF., AGUIAR AO. Indicadores de Desenvolvimento Sustentável. In: Philippi Jr A (ed.). Saneamento, saúde e ambiente: fundamentos para o desenvolvimento sustentável. Barueri, SP: Nisam. Editora Manole Ltda; 2005.

PHILIPPI JR A. et al. Indicadores de desenvolvimento sustentável: um estudo de caso da estância turística de Ribeirão Pires. In: CONGRESSO INTERNACIONAL EM PLANEJAMENTO E GESTÃO AMBIENTAL Urbenviron. Brasília Universidade Católica de Brasília, 2005.

PMSA-PREFEITURA MUNICIPAL DE SANTO ANDRÉ. Mapa da Região Metropolitana: destaque para Santo André. Santo André: Secretaria de Habitação e Desenvolvimento, 2003.

PMSA-PREFEITURA MUNICIPAL DE SANTO ANDRÉ. Sistematização das Discussões de 2002. Santo André, Secretaria de Orçamento e Planejamento Participativo, 2003b.

PMSA-PREFEITURA MUNICIPAL DE SANTO ANDRÉ. Sumário de Dados de Santo André 2004: Ano Base 2003. Santo André, Secretaria de Orçamento e Planejamento Participativo, 2004a.

PMSA-PREFEITURA MUNICIPAL DE SANTO ANDRÉ. Sumário de Dados de Paranapiacada e Parque Andreense 2004: Ano Base 2003. Santo André: Subprefeitura de Paranapiacaba e Parque Andreense, 2004b. Disponível em URL <http://www.santoandre.sp.gov.br/bn_conteudo. asp? $\operatorname{cod}=4819>25 / 02 / 2005$.

PMSA, CIDA- PREFEITURA MUNICIPAL DE SANTO ANDRÉ, AGÊNCIA CANADENSE PARA O DESENVOLVIMENTO INTERNACIONAL. Desenvolvimento Econômico, Comunitário e Turismo para Inclusão Social. Projeto Gepam, 5. São Paulo: Annablume, 2004.
SANTO ANDRÉ. Lei no 8.696 de 30 de março de 2004. Dispõe sobre a instituição do Plano Diretor Participativo do Município de Santo André. Disponível em URL < http://www.santoandre. sp.gov.br> 05/05/05.

SANTO ANDRÉ. Lei no 7733 de 14 de outubro de 1998. Dispõe sobre a instituição da Política Municipal de Gestáo e Saneamento Ambiental do Município de Santo André. In: Caderno sobre a Política Municipal de Gestão e Saneamento Ambiental de Santo André. Santo André: Serviço Municipal de Saneamento Ambiental de Santo André, 2005.

SIENA, O. Método para Avaliar Progresso em Direção ao Desenvolvimento Sustentável. [tese de doutorado apresentada ao Programa de Pós-Graduação em Engenharia de Produção da Universidade Federal de Santa Catarina]. Florianópolis, 2002.

VAN BELLEN, H.M. Indicadores de Sustentabilidade: uma análise comparativa. Florianópolis, 2002. [Tese de doutorado apresentada para o Centro Tecnológico da Universidade Federal de Santa Catarina]. Disponível em URL <http://teses.eps.ufsc.br/defesa/pdf/4733.pdf> $11 / 02 / 2005$.

Endereço para correspondência:

Juliana Pellegrini Cezare

Faculdade de Saúde Pública e

Escola de Engenharia de São

Carlos - USP

Projeto SIADES - Sistema de

Informações Ambientais para o

Desenvolvimento Sustentável

Av. Dr. Arnaldo 715

0 I 246-904 São Paulo - SP - Brasil

Tel.: (I I) 306 I 77 I 2

E-mail: siades@fsp.usp.br 